\title{
PAPERS
}

\section{Treating hypertension in black compared with white non-insulin dependent diabetics: a double blind trial of verapamil and metoprolol}

\author{
J K Cruickshank, N McF Anderson, J Wadsworth, S McHardy Young, E Jepson
}

\begin{abstract}
Study objective-To compare responses of blood pressure to the calcium antagonist verapamil and the $\beta$ blocker metoprolol in black compared with white diabetics with hypertension and to monitor urinary albumin excretion in relation to fall in blood pressure.
\end{abstract}

Design-Double blind, placebo controlled, random order crossover trial with four week placebo run in period and two six week active phases separated by a two week placebo washout period.

Setting-Outpatient department of a general hospital in a multiethnic health department.

Patients-Diabetic patients with hypertension. Four dropped out before randomisation; 25 black and 14 white patients completed the trial.

Interventions-Patients given slow release verapamil $120 \mathrm{mg}$ or $240 \mathrm{mg}$ twice daily with placebo or metoprolol $50 \mathrm{mg}$ or $100 \mathrm{mg}$ twice daily with placebo. Treatment for diabetes (diet alone or with oral hypoglycaemic drugs) remained unchanged.

End point-Comparison of changes in blood pressure in the two groups taking both drugs.

Measurements and main results-Metoprolol had little effect on blood pressure in black patients (mean fall $4.0 \mathrm{~mm} \mathrm{Hg}$ systolic $(95 \%$ confidence interval -2.5 to $10.4 \mathrm{~mm} \mathrm{Hg}), 4.3 \mathrm{~mm} \mathrm{Hg}$ diastolic $(-0.8$ to 9.5)) but more effect in white patients (mean falls $13.4 \mathrm{~mm} \mathrm{Hg}(0.1$ to 26.7$)$ and $10.6 \mathrm{~mm} \mathrm{Hg} \mathrm{(4.5} \mathrm{to}$ 16.7) respectively). Verapamil was more effective in both groups, with mean falls of $8.8 \mathrm{~mm} \mathrm{Hg}(2.4$ to and $19.1 \mathrm{~mm} \mathrm{Hg}(5.4$ to 32.9$)$ and $11.4 \mathrm{~mm} \mathrm{Hg} \mathrm{(0.9} \mathrm{to}$ 22.0 ) in white patients. Heart fate fell significantly in black patients taking metoprolol, which suggested compliance with treatment. Metabolic variables were unaltered by either treatment. Plasma renin activity was low in both groups after metoprolol treatment, but change in blood pressure could not be predicted from baseline plasma renin activity. Urinary albumin:creatinine ratio was independently related to baseline blood pressure but not significantly changed by treatment.

Conclusions $-\beta$ Blockers alone are not effective in treating hypertension in black diabetics. Verapamil is effective but less so than in white patients. As yet no ideal monotherapy exists for hypertension in black patients.

St Mary's Hospital Medical School, London W2

J Wadsworth, MSC, lecturer in medical statistics

Correspondence to: Dr J K Cruickshank, Department of Medicine and MRC

Epidemiology and Medical Care Unit, Northwick Park Hospital, Harrow HA1 3UJ.

\section{Introduction}

Black people of West Indian descent in Britain are generally thought to have more problems with hypertension than white people and to be less easy to treat because they may not take their tablets and hence have more complications. Evidence for this view is poor. Contrary to experience in the United States recent studies in Britain found no difference in average blood $15.0)$ and $8.1 \mathrm{~mm} \mathrm{Hg} \mathrm{(5.0} \mathrm{to} 11.2)$ in black patients

pressure between black and white subjects but found a higher body mass index in black women. ${ }^{12}$ The rate of coronary heart disease in black people has been about half that in white people, a deficit not made up by the increased rate of strokes in black people occurring at an older age ${ }^{34}$ Causes other than coronary heart disease are thus more important in black people.

Standardised mortality ratios for hypertension and particularly for diabetes are high in people of West Indian or African birth. ${ }^{3}$ The two conditions (diabetes being almost exclusively non-insulin dependent) commonly occur together in middle and old age. Effective treatment of hypertension is vital. ${ }^{8-10}$ The choice of treatment, however, is awkward: although diuretics are reported to be more effective than $\beta$ blockers in black Americans, possibly because black people tend to have low renin hypertension, they cause hyperglycaemia. ${ }^{112}$ Angiotensin converting enzyme inhibitors have the same limitations,${ }^{13}$ though calcium antagonists may be more effective in patients with low renin hypertension. ${ }^{14}$

The lack of effect of $\beta$ blockers is sometimes blamed on poor compliance with treatment by black patients. To test this in a clinical trial and to compare results with those obtained with a calcium antagonist we mounted a randomised double blind controlled trial of a calcium antagonist (verapamil) and a $\beta$ blocker (metoprolol) in black compared with white diabetics. We also examined whether controlling high blood pressure altered or reduced urinary albumin excretion even within its normal range.

\section{Methods}

Patients aged up to 70 were invited to join the trial if their blood pressure was high $(>160 \mathrm{~mm} \mathrm{Hg}$ systolic or $>95 \mathrm{~mm} \mathrm{Hg}$ diastolic) on two occasions on routine screening in the diabetic clinics at Central Middlesex and Willesden Hospitals or if they were known to have hypertension and were not taking more than two treatments. All the patients had non-insulin dependent diabetes and were treated with either diet alone or diet and oral hypoglycaemic drugs. They had normal renal function (plasma creatinine concentration $<130$ $\mu \mathrm{mol} / \mathrm{l})$, and their urine yielded negative results on dip stick testing for albumin. The black patients were all of West Indian and hence African descent and had been born in the West Indies; we specifically excluded West Indian people of east Indian origin and black Africans. The white patients were all Europeans.

We used a double blind randomised crossover 
active drug and placebo for a further six weeks. They were reviewed every fortnight for four visits to check for a rise in blood pressure $>200 \mathrm{~mm} \mathrm{Hg}$ systolic or $>110 \mathrm{~mm} \mathrm{Hg}$ diastolic, or both, which was a criterion for withdrawal, or to increase the drug dose if the target blood pressure of $<150 \mathrm{~mm} \mathrm{Hg}$ systolic or $<90 \mathrm{~mm} \mathrm{Hg}$ diastolic had not been reached. To detect a difference of $5 \mathrm{~mm} \mathrm{Hg}$ in the fall of blood pressure between the drugs, with $90 \%$ power at $\mathrm{p}<0.05$, about 40 subjects were required. To show a difference of $8 \mathrm{~mm} \mathrm{Hg}$ between ethnic groups-that is, that the calcium antagonist was more effective in one than the otherrequired 15-20 subjects in each group. The numbers of black and white patients were determined by those available from routine screening at the diabetic clinics.

Drugs were packed as active drug or matching placebo, the randomisation code being unknown to the investigators. As a few reports have suggested a possible hyperglycaemic effect of nifedipine we chose a slow release formulation of verapamil $(120$ or $240 \mathrm{mg}$ twice daily) selected as the calcium antagonist. Metoprolol 50 or $100 \mathrm{mg}$ twice daily was chosen as the $\beta$ blocker. Patients began by taking the lowest dose of each drug but were subsequently given the higher dose if necessary. As a double dummy method was used patients had to take two to four tablets (one or two active and one or two placebo) twice daily as necessary in addition to their usual (and unchanged) diabetic treatment. Patients were asked to fast overnight before visiting the clinic and to take the morning dose two to four hours before being seen.

We measured each subject's height at the first visit, and weight at each visit, to calculate body mass index $\left(\mathrm{kg} / \mathrm{m}^{2}\right)$. Blood pressure was measured with a Hawksley random zero sphygmomanometer, with a large cuff for arm circumference $>33 \mathrm{~cm}$, while the patients were lying $(>5$ minutes) and standing $(>1$ minute), taking diastolic pressure at phase $\mathrm{V}$ of the Korotkoff sounds. The mean of two readings in each

TABLE I-Baseline data on patients in trial

\begin{tabular}{|c|c|c|}
\hline & $\begin{array}{l}\text { Black patients } \\
\quad(\mathbf{n}=25)\end{array}$ & $\begin{array}{l}\text { White patients } \\
\quad(n=14)\end{array}$ \\
\hline Mean (SD) age (years) & $58 \cdot 1(3 \cdot 7)$ & $64 \cdot 2(5 \cdot 3)$ \\
\hline No of men & 13 & \\
\hline Mean (SD) known duration of diabetes (years) & $6 \cdot 2(4 \cdot 9)$ & $5 \cdot 8(4 \cdot 7)$ \\
\hline Mean (SD) body mass index $\left(\mathrm{kg} / \mathrm{m}^{2}\right)$ & $28 \cdot 8(3 \cdot 4)$ & $30 \cdot 1(4 \cdot 7)$ \\
\hline \multicolumn{3}{|l|}{ No $(\%)$ treated with: } \\
\hline Diet alone & $3(12)$ & $1(7)$ \\
\hline Diet and metformin & $7(28)$ & $4(29)$ \\
\hline Diet and glibenclamide & $3(12)$ & $2(14)$ \\
\hline Diet and both drugs & $12(48)$ & $7(50)$ \\
\hline \multicolumn{3}{|l|}{ No (\%) with complications: } \\
\hline Neuropathy & $11(44)$ & $6(43)$ \\
\hline Background retinopathy & $6(24)$ & $3(21)$ \\
\hline
\end{tabular}

TABLE II - Mean (SD) standing blood pressure and heart rate at start and end of each treatment in 25 black patients and 14 white patients

\begin{tabular}{|c|c|c|c|c|}
\hline & \multicolumn{2}{|c|}{ Metoprolol } & \multicolumn{2}{|c|}{ Verapamil } \\
\hline & Black patients & White patients & Black patients & White patients \\
\hline \multicolumn{5}{|c|}{ Systolic pressure $(\mathrm{mm} \mathrm{Hg})$} \\
\hline $\begin{array}{l}\text { Start } \\
\text { End }\end{array}$ & $\begin{array}{l}166 \cdot 7(17 \cdot 0) \\
162 \cdot 5(20 \cdot 3)\end{array}$ & $\begin{array}{l}171 \cdot 1(17 \cdot 8) \\
157 \cdot 7(23 \cdot 2)\end{array}$ & $\begin{array}{l}165 \cdot 2(15 \cdot 9) \\
156 \cdot 4(14 \cdot 1)\end{array}$ & $\begin{array}{l}165 \cdot 6(15 \cdot 7) \\
146 \cdot 4(19 \cdot 5)\end{array}$ \\
\hline $\begin{array}{l}\text { Mean paired differences } \\
(95 \% \text { confidence interval })\end{array}$ & $4 \cdot 0(-2 \cdot 5$ to $10 \cdot 4)$ & $13 \cdot 4(0 \cdot 1$ to $26 \cdot 7)$ & $8 \cdot 8(2 \cdot 4$ to $15 \cdot 0)$ & $19 \cdot 1(5 \cdot 4$ to $32 \cdot 9)$ \\
\hline \multicolumn{5}{|c|}{ Diastolic pressure $(\mathrm{mm} \mathrm{Hg})$} \\
\hline $\begin{array}{l}\text { Start } \\
\text { End } \\
\text { Mean paired differences }\end{array}$ & $\begin{array}{r}101 \cdot 0(10 \cdot 9) \\
96 \cdot 8(16 \cdot 0)\end{array}$ & $\begin{array}{l}97 \cdot 1(8 \cdot 4) \\
86 \cdot 5(14 \cdot 8)\end{array}$ & $\begin{array}{r}100 \cdot 9(15 \cdot 9) \\
93 \cdot 9(11 \cdot 2)\end{array}$ & $\begin{array}{l}95 \cdot 6(11 \cdot 4) \\
84 \cdot 2(14 \cdot 9)\end{array}$ \\
\hline ( $95 \%$ confidence interval) & $4 \cdot 3(-0.8$ to $9 \cdot 5)$ & $10 \cdot 6(4 \cdot 5$ to $16 \cdot 7)$ & $8 \cdot 1(5 \cdot 0$ to $11 \cdot 2)$ & $11.4(0.9$ to $22 \cdot 0)$ \\
\hline \multicolumn{5}{|c|}{ Heart rate (beats/min) } \\
\hline $\begin{array}{l}\text { Start } \\
\text { End } \\
\text { Mean paired differences }{ }^{\star}\end{array}$ & $\begin{array}{l}76 \cdot 4(13 \cdot 5) \\
62 \cdot 5(8 \cdot 9)\end{array}$ & $\begin{array}{l}83 \cdot 1(16 \cdot 2) \\
62 \cdot 3(11 \cdot 9)\end{array}$ & $\begin{array}{l}76 \cdot 2(12 \cdot 9) \\
72 \cdot 0(11 \cdot 4)\end{array}$ & $\begin{array}{l}84 \cdot 0(13 \cdot 7) \\
79 \cdot 2(11 \cdot 1)\end{array}$ \\
\hline ( $95 \%$ confidence interval) & $14.0(8 \cdot 9$ to $19 \cdot 1)$ & $17 \cdot 7(10 \cdot 0$ to $25 \cdot 4)$ & $1.9(-1.7$ to $5 \cdot 5)$ & $4 \cdot 5(-3 \cdot 4$ to $12 \cdot 5)$ \\
\hline
\end{tabular}

^Because of missing results paired differences may not equal difference between values at start and end. position and pulse rates over 30 seconds were recorded by one observer. The presence of diabetic complications was assessed at the first visit, when fundi were examined through dilated pupils. Peripheral neuropathy was considered to be present if ankle jerks were absent on reinforcement, and autonomic neuropathy if there was a postural drop of $>20 \mathrm{~mm} \mathrm{Hg}$ systolic blood pressure or lack of reflex tachycardia in an electrocardiogram obtained during the Valsalva manoeuvre. Electrocardiograms were taken at the start, middle, and end of each active treatment phase.

Blood samples were taken while the patients were fasting and tested for plasma electrolyte, creatinine, albumin, total and high density lipoprotein cholesterol concentrations, whole venous blood glucose, and haemoglobin $A_{1}$ concentrations (using a modified column method). Plasma renin activity in blood in edetic acid was measured together with serum $\mathrm{C}$ peptide concentration, both by standard radioimmunoassay. Timed overnight collections of urine were made after the bladder was emptied at night and included the first sample in the morning. Aliquots were assayed for electrolyte, creatinine, and albumin concentrations. Albumin concentration was measured by competitive radioimmunoassay with $100 \mu \mathrm{l}$ rabbit antihuman albumin (diluted 1/150). After overnight incubation a layer of $100 \mu \mathrm{l}$ sheep antirabbit IgG (diluted 1/10) was applied for albumin concentrations down to $5 \mathrm{mg} / \mathrm{l}$; for a sensitised assay down to $100 \mu \mathrm{g} / \mathrm{l}$ neat donkey antirabbit IgG was incubated for one hour at room temperature. Counts were recorded with a gammacounter after 30 minutes' centrifugation.

Urinary electrolyte, creatinine, albumin concentrations; blood glucose, haemoglobin $A_{1}$, and $C$ peptide concentrations; and plasma renin activity were logarithmically transformed before analysis with the statistical package for the social sciences (SPSS-X). Statistical analysis was by $t$ tests, analysis of variance, and analysis of covariance as appropriate.

The protocol was passed by Brent Health District's ethics committee.

\section{Results}

Recruitment was stopped after 27 black and 16 white patients had entered the run in placebo period. Two black and two white patients withdrew before randomisation (one owing to impaired renal function). The remaining 25 black and 14 white patients completed the trial.

The characteristics of the patients, including known duration of diabetes, were comparable, though the black patients were slightly younger, had a lower body mass index, and contained a larger proportion of women (Table I). The number taking oral hypoglycaemic drugs was similar in both groups; the average dose was $850 \mathrm{mg}$ metformin alone twice daily, $7 \cdot 5-10.0 \mathrm{mg}$ glibenclamide alone daily, or $850 \mathrm{mg}$ metformin plus $7 \cdot 5 \mathrm{mg}$ glibenclamide daily. Complications of diabetes were mild (table I); no patient had autonomic neuropathy, and one white and one black patient had had laser treatment for proliferative retinopathy.

In the verapamil phase of the study 17 of the 25 black patients and seven of the 14 white patients required an increase in the dose to $240 \mathrm{mg}$ twice daily. All the black patients took the higher dose of metoprolol as did nine of the white patients. Compliance was generally excellent based on tablet counts, with $<8 \%$ of tablets returned on any visit.

There was no significant difference in baseline systolic and diastolic pressures at the start of each treatment phase either within groups or between groups by analysis of variance (table II), although the white patients tended to have lower diastolic pressures. 
In the black patients there was no overall fall in either systolic or diastolic pressure when they were taking metoprolol, with $95 \%$ confidence intervals for both pressures including zero $(t=0.75$ diastolic and 0.8 systolic; $\mathrm{df}=24 ; \mathrm{p}>0.4)$; in the white patients systolic (with a wide confidence interval) and diastolic pressures fell when they were taking metoprolol (mean $=12.0 \mathrm{~mm} \mathrm{Hg} ; t=3.75$ diastolic and 2.18 systolic; $\mathrm{df}=13 ; \mathrm{p}=0.002$ and 0.048 respectively). The overall fall in blood pressure was greater with verapamil than metoprolol and was greater in white than black patients (table II). Individual values confirmed these mean results, with only five of the black patients showing falls in blood pressure $>8 \mathrm{~mm} \mathrm{Hg}$ while taking metoprolol (fig 1); only two of the white patients had falls $<8 \mathrm{~mm} \mathrm{Hg}$. In the 14 white patients blood pressure fell with both drugs; there was a consistent dose response which was greater than that in the black patients, whose blood pressures had fallen at two weeks but no further by. six weeks (fig 2). These differences remained significant when age and differences in baseline blood pressure were taken into account by analysis of covariance.

Though blood pressure did not fall in the black patients when they took metoprolol, heart rates fell significantly and only slightly less than in white patients (table II). No overall change was seen when patients took verapamil. Changes in heart rate and in blood pressure were not correlated, either in those black patients in whom there was at least some fall in pressure or in the white patients, or in the groups combined.

\section{METABOLIC RESULTS}

Glycaemic, lipid, and $C$ peptide profiles-Analysis of variance showed that mean haemoglobin $A_{1}$ concentrations were unaltered during each treatment phase in black and white patients (baseline values $11 \cdot 1 \%$ and $9 \cdot 2 \%$ respectively); similarly fasting blood glucose concentrations were unchanged, though values were higher throughout in the black than the white patients (overall mean (SD) 9.5 (1.4) $v 7.7(1.3) \mathrm{mmol} / \mathrm{l}$, respectively; $\mathrm{p}<0.01)$. The serum total cholesterol concentrations were also unchanged during each treatment period but were significantly lower in the black than white patients (overall mean $5.96(1.4) v 6.36(1 \cdot 1)$ $\left.\mathrm{mmol} / \mathrm{l} ; \mathrm{F}_{1,218}=8 \cdot 2 ; \mathrm{p}<0.01\right)$, yet the concentration of high density lipoprotein cholesterol was considerably higher in the black than white patients $(1.57(0.39) v$

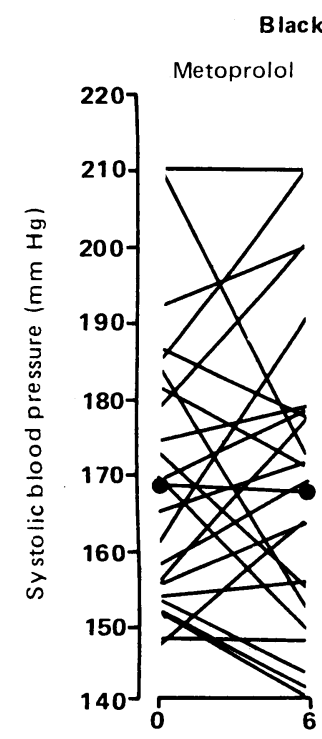

Black patients

Verapamil

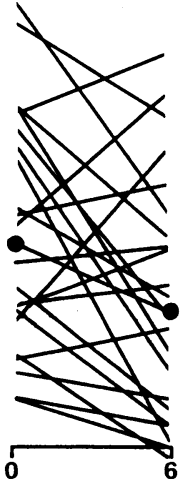

White patients

Metoprolol Verapamil
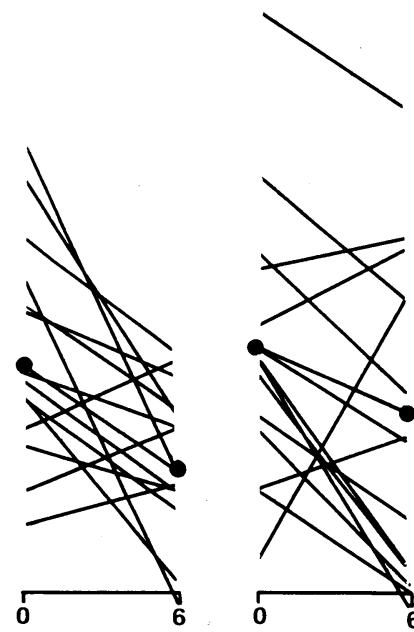

Weeks

FIG 1 - Individual changes in supine systolic blood pressure at baseline and six weeks for each drug. Overall means shown by bold line

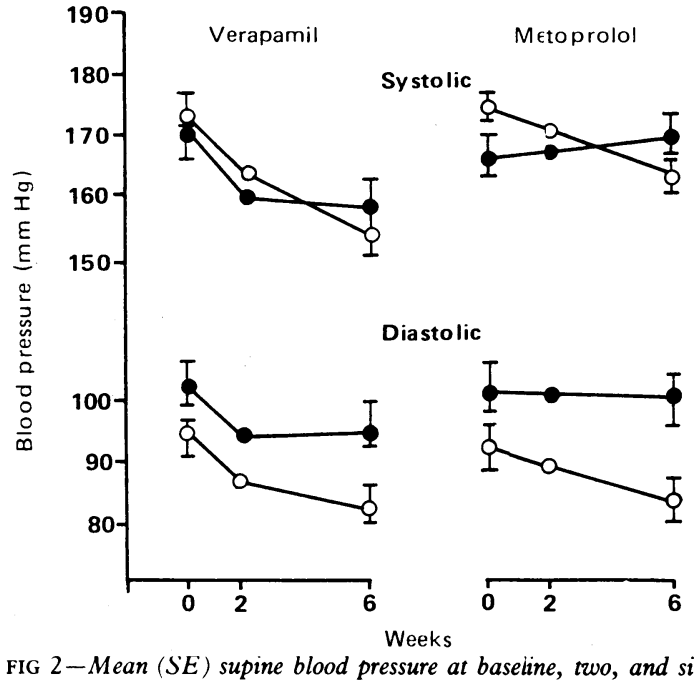

FIG 2-Mean (SE) supine blood pressure at baseline, two, and six White patients

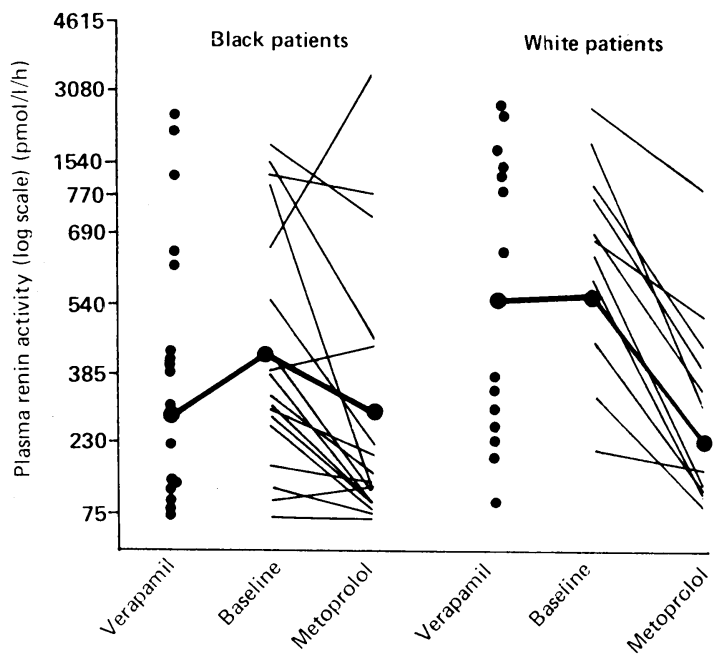

FIG 3-Plasma renin activity at baseline and end of treatments. Individual changes are shown for metoprolol but not for verapamil, which did not suppress activity overall. Overall means shown by bold line

$\left.1 \cdot 15(0 \cdot 2) \mathrm{mmol} / \mathrm{l} ; \mathrm{F}_{1,214}=42 \cdot 3 ; \mathrm{p}<0 \cdot 001\right)$ and was also unchanged during treatment. Plasma $\mathrm{C}$ peptide concentration, an important index of insulin secretion, was unchanged during treatment in either group, though it was significantly lower in the black patients (overall geometric mean $0.45 v 0.79 ; \mathrm{F}_{1,97}=39 \cdot 1$; $\mathrm{p}<0.0001)$.

Plasma renin activity - The geometric mean plasma renin activity was low in both groups and was significantly lower in the black than white patients initially $(0.42 v 0.55 \mathrm{nmol} / \mathrm{l} / \mathrm{h})$ and after verapamil treatment $(p<0.001)$ (fig 3). In both groups, though to a lesser extent in black patients and despite the lack of a fall in blood pressure, the activity was further suppressed by metoprolol. There was no significant relation between change in blood pressure and baseline renin activity or change in renin activity.

Urine albumin, creatinine, and electrolyte concentrations-Urinary albumin excretion, measured in timed overnight samples on six occasions over 18 weeks, was within the normal range $(<30 \mathrm{mg} / \mathrm{l})$ in both the white and black patients except in one black woman with microalbuminuria (in whom it varied from 66 to 149 $\mathrm{mg} / \mathrm{l}$ ). Using the ratio of urinary albumin to creatinine excretions to correct for volume produced similar results. Throughout the trial urinary creatinine excretion was slightly higher in the black than white patients (geometric mean $4.61 v 3.59 \mathrm{mmol} / \mathrm{l}$; $\mathrm{p}<0.05$ by analysis of covariance after accounting for 
differences in age). Urinary electrolyte concentrations did not differ between the groups or through the trial. The mean change in the urinary albumin:creatinine ratio between the start and end of either treatment was a decrease of $20.3 \%$ (from 0.78 to 0.64 ) for 60 paired values ( $95 \%$ confidence interval $23 \%$ to $-89 \%$ ). Thus the treatment had no significant effect on urinary albumin:creatinine ratio (or urinary albumin). Baseline urinary albumin excretion was, however, related to initial systolic blood pressure in the group as a whole, both supine $(\mathrm{r}=0.28 ; \mathrm{n}=39 ; \mathrm{p}<0.02)$ and standing $(r=0.35 ; \mathrm{p}<0.01)$, owing to a stronger relation in the black patients (supine $r=0 \cdot 36$; standing $\mathrm{r}=0.55$ ).

\section{Discussion}

This study confirms the limited effect of a $\beta$ blocker in black patients: the mean blood pressure did not fall when the patients took metoprolol, though there was a limited response in individual patients. The effect of verapamil in reducing blood pressure was more uniform among the black patients, averaging $9 / 8 \mathrm{~mm}$ $\mathrm{Hg}$, but was more pronounced in the white patients $(19 / 11 \mathrm{~mm} \mathrm{Hg})$. Despite some differences in baseline factors between the black and white patients the analysis of variance substantiated the difference in drug response between black and white people. A crossover trial, particularly with a placebo run in period and a double dummy technique, is one method of dealing with the fall in blood pressure that occurs with repeated measurements.

To our knowledge there are no previously published trials on blood pressure specifically comparing black with white patients in Britain, where $\beta$ blockers remain common as monotherapy. About half of the black patients with hypertension referred to our clinic from general practice and taking monotherapy are taking $\beta$ blockers, though the limitations of these drugs in black patients have been described in double blind trials. One trial, of atenolol, was carried out in South Africa, ${ }^{15}$ where social conditions are poor and black people are of different genetic origin to those whom we studied. In the United States the Veterans Administration trial of parallel design compared propranolol and hydrochlorothiazide and found similar results. ${ }^{112}$ A study from Jamaica showed that black patients required higher doses of atenolol and responded better to chlorthalidone (a thiazide). ${ }^{16}$ The difference in response between black and white patients is abolished when black patients take a thiazide with the $\beta$ blocker. This has been shown in black patients of different origins in the United States, ${ }^{17}$ the Caribbean, ${ }^{18}$ and Kenya (N Poulter, personal communication).

A clear dissociation was seen in our study between the response of the heart rate to the $\beta$ blocker and the lack of fall in blood pressure in the black patients. Their mean fall in heart rate was about 14 beats/ minute, which was much the same as that in the white patients ( 17 beats/minute); no overall change occurred when either group took verapamil. This indicated compliance with the treatment among both groups of patients and tablet counts showed that over $92 \%$ of tablets had been taken at every visit.

The poor response of blood pressure to $\beta$ blockers in black patients has been related to low plasma renin activity. ${ }^{12} 19$ In our patients renin activity was already low, and this may be a feature of diabetics with hypertension in any ethnic group. ${ }^{8}$ Renin activity was slightly suppressed in the black patients while they received the $\beta$ blocker (fig 3 ) but did not help to predict individual response to treatment. In the white patients and in the groups combined there was no relation between initial renin activity and change in blood pressure, contrary to previous reports. ${ }^{14}$
The mechanism of suppression of renin in black populations, which is present in early childhood, is unknown. ${ }^{20}$ Estimates of urinary sodium excretion do not support excess salt intake as a cause of the lower renin activity in black people, whether as children or adults. ${ }^{21}{ }^{22}$ No difference in sodium excretion between or within groups was found on the six occasions that it was measured here.

The response to verapamil suggests that it is a useful treatment for hypertension in both black and white patients. One other study, parallel in design, compared verapamil with propranolol in non-diabetic black and white patients in the United States. ${ }^{23}$ It did not compare the responses to the two drugs within patients, but its results were similar to ours and showed the limited effect of propranolol compared with verapamil in black patients and a greater response to verapamil in the white patients. A recent multicentre study of the calcium antagonist diltiazem reported similar results, with the poor response in black patients increased by the addition of hydrochlorothiazide. ${ }^{24}$ This again suggests that to maximise the response of blood pressure to calcium antagonists in black patients diuretics should be added to treatment.

Metabolic ill effects were not observed during the trial. The higher mean $C$ peptide concentration among the white patients probably reflects their higher body mass index, but the $C$ peptide concentration was unaltered in both groups by either treatment. Fears that calcium antagonists might impair glucose tolerance were not supported here or by previous data on verapamil. ${ }^{25}$ Changes in lipid concentrations were not detected; the lower total cholesterol and considerably higher high density lipoprotein cholesterol concentrations in these black diabetics is consistent with the few data on non-diabetic black subjects in Britain ${ }^{26}$ and in the Caribbean and in line with their much lower risk of coronary disease. ${ }^{27} 28$

No effect on urinary albumin excretion was seen, but this study was too small to detect an overall effect or a difference between drugs. Possibly, afferent renal arteriolar blood pressure is the main determinant of filtration pressure and hence urinary albumin excretion, which may also be modified by the effects of drugs on the efferent renal arteriole. If so, $\beta$ blockers with no effect on renal blood flow (such as metoprolol) would alter urinary albumin concentration less than other drugs (such as angiotensin converting enzyme inhibitors and calcium antagonists). A beneficial effect of captopril on protein loss in overt diabetic nephropathy has been reported in two studies. ${ }^{29} 30$ In a third study the fall in glomerular filtration over two years was slowed down, though the relation to change in blood pressure was not examined. ${ }^{31}$ In our study the $95 \%$ confidence interval for the change in the ratio of urinary albumin to creatinine excretion between the start and end of treatment was large. At least twice the number of patients would be required to test the hypothesis that reducing the blood pressure of hypertensive diabetics decreases albumin excretion even within its normal range.

The baseline urinary albumin excretion was positively correlated with initial systolic blood pressure. This relation was independent of age, body mass, and haemoglobin $A_{1}$ concentration. We recently reported similar findings: in non-diabetics the ratio of urinary albumin to creatinine excretion in a spot sample of urine collected during the day was related to systolic blood pressure in a random sample of non-diabetics with normal renal function ${ }^{32}$ and in a random sample from a diabetic population. ${ }^{33}$ Thus, epidemiologically and possibly clinically, urine albumin excretion may reflect the blood pressure.

In conclusion, it seems that even with drugs such as calcium antagonists, to which black patients do 
respond, the degree of response of blood pressure is less for a given dose in black than white patients. There are no ideal antihypertensive drugs for black patients, and these data suggest that poor compliance does not account for the failure to control blood pressure.

We thank Knoll AG (Burgess Hill) for supplying verapamil and placebo; Astra Ltd (Stoke Poges) for supplying metoprolol and placebo; Dr Peter Frost and colleagues for measuring serum electrolyte and lipid concentrations; Drs Shore and MacGregor (Charing Cross Hospital) for measuring plasma renin activity; Mrs Burnett and Dr Turner (Oxford) for measuring C peptide concentrations; and Nicola Wilson Smith for typing the manuscript. Some of the data were presented at the meeting of the International Society of Hypertension, Heidelberg, 1986. ${ }^{34}$

NMcFA received support from Knoll AG.

1 Cruickshank JK, Jackson S, Beevers G, Bannan L, Beevers M, Stewart Similarity of blood pressure in blacks, whites and Asians in England: Similarity of blood pressure in blacks, whites and
Birmingham factory study. F Hypertens 1985;3:365-71.

2 Haines AP, Booroff A, Goldenberg E, Morgan P, Singh M, Wallace P. Blood pressure, smoking, obesity and alcohol consumption in black and white patients in general practice. Foumal of Human Hypertension 1987;1:39-46.

3 Marmot MG, Bulusu L, Adelstein A. Immigrant mortality in England and Wales. London: HMSO, 1984

4 Cruickshank JK, Beevers DG, Osborne V, et al. Heart attack, stroke, diabetes and hypertension in West Indians, Asians and whites in Birmingham, England. Br Med f 1980;281:1108.

5 Pacy P, Dodson P, Beevers M, Fletcher R, Taylor $K$. The ethnic prevalence of hypertension in a diabetic clinic. Postgrad Med f 1983;59:637-40.

6 Cruickshank JK, Alleyne S. Vascular disease in West Indian and white diabetics in Britain compared with Jamaica. Postgrad Med $\mathcal{F} 1981 ; 57: 766-8$.

7 Cruickshank JK, Alleyne S. Black West Indian and matched white diabetics in Britain compared with diabetics in Jamaica: body mass, blood pressure and vascular disease. Diabetes Care 1987;10:170-9.

8 Drury PL. Diabetes and arterial hypertension. Diabetologia 1983;24:1-9.

9 Parving H, Andersen A, Schmidt U, Svendsen P. Early aggressive antihypertensive treatment reduces rate of decline in kidney function in diabetic nephropathy. Lancet 1983;i:1175-9.

10 Hostetter T, Rennke H, Brenner B. The case for intrarenal hypertension in the initiation and progression of diabetic and other glomerulopathies. $\mathrm{Am}$ f Med 1982;72:375-80.

11 Veterans Administration Study Group. Comparison of propranolol and hydrochlor-thiazide for initial treatment of hypertension. I. Results of shortterm titration with emphasis on racial differences in response. IAMA 1982;248:1996-2004

12 Freis ES, Materson B, Flamenbaum W. Comparison of propranolol and hydrochlorthiazide in hypertension: evaluation of renin-angiotensin system. hydrochlorthiazide in hyper

13 Veterans Administration cooperative study. Racial differences in response to low dose captopril are abolished by the addition of hydrochlorthiazide. $B r \mathcal{F}$ Clin Pharmacol 1982;14(suppl 2):97-102.

14 Bühler F, Hulthen UL, Kiowski W, Bolli P. Greater anti-hypertensive efficacy of the calcium channel inhibitor verapamil in older and low renin patients. Clin Sci 1982:63(suppl 8):439-42.

15 Seedat YK. Trial of atenolol and chlorthalidone for hypertension in black South Africans. Br Med $\mathcal{F}$ 1980;281:1241-2.

16 Grell G, Alleyne G, Robinson H, Anderson N. Treatment of Jamaican hypertensives with atenolol and chlorthalidone. West Indian Med f 1981;30: 124-8

17 Moser N, Lunn J. Comparative effects of pindolol and hydrochlorothiazide in black hypertensive patients. Angiology 1981;32:561-6.

18 Grell GAC, Forrester TE, Anderson M, Gibbs P. Oxprenolol and chlorthaldone in the treatment of mild hypertension in Jamaica. Tropical Cardiolog 1987;13:157-63.

19 Cruickshank JK, Beevers DG. Ethnic and geographic differences in blood pressure. In: Bulpitt C, ed. Epidemiology of hypertension. Cambridge: Elsevier, 1985:70-87.

20 Cresanta JC, Burke GL. Determinants of blood pressure levels in children and adolescents. In: Berenson GS, ed. Causation of cardiovascular risk factors in children. New York: Raven Press, 1986:171-2.

21 Berenson GS, Voors AW, Webber LS, Dalferes ER, Haksha DW. Racial differences in parameters associated with blood pressure levels in childrenthe Bogars part

22 Luft FC, Grimm CE, Fineberg N, Weinberger ME. Effects of volum expansion and contraction in normotensive whites, blacks and subjects of different ages. Circulation 1979;59:643-51.

23 Cubeddu LX, Aranda J, Singh B, et al. Comparison of verapamil and propranolol for the initial treatment of hypertension. JAMA 1986;256: 2214-21

24 Massie B, McCarthy P, Ramanathan K, et al. Diltiazam and propranolol in mild to moderate essential hypertension. Ann Intern Med 1987;107:150-7.

25 Andersson DE, Rojdmark S. Improvement of glucose tolerance by verapam in patients with non-insulin dependent diabetes mellitus. Acta Med Scand 1981;210:27-33.

26 Miller GJ. Lipids and coagulation factors. In: Cruickshank JK, Beevers DG eds. Ethnic factors in health and disease. London: Butterworth (in press).

27 Miller GJ, Miller NE, Ashcroft MT. Inverse relationship in Jamaica between plasma HDL-cholesterol and coronary disease risk as predicted by multiple plasma HDL-cholesterol and coronary disease risk
risk factor status. Clin Sci Mol Med 1976;51:475-82.

28 Beckles GLA, Miller GJ, Kirkwood BR, et al. High total and cardiovascular disease mortality in adults of Indian descent in Trinidad, unexplained by major coronary risk factors. Lancet 1986; i: 1298-1301.

29 Taguma Y, Katamoto Y, Futaki G, Ueda $\mathrm{H}$, et al. Effect of captopril on heavy proteinuria in azotemic diabetics. $N$ Engl $\mathcal{G}$ Med 1985;313:1617-20.

30 Hómmel E, Parving HH, Mathiesen E, et al. Effect of captopril on kidney function in insulin-dependent diabetic patients with nephropathy. $\mathrm{Br} \mathrm{Med}$ $1986 ; 293: 467-70$

31 Bjorck S, Byberg G, Mulec $\mathrm{H}$, et al. Beneficial effects of angiotensin converting enzyme inhibition on renal function in patients with diabetic nephropathy. BrMed f 1986;293:471-4.

32 Cruickshank JK, Anderson NMcF, Haines AP. 'Spot' urinary albumin/ creatinine: a positive independent relation to systolic blood pressure in the general population, an index of vascular risk? Clin Sci 1987;72(suppl 16):43. [Abstract.]

33 Cruickshank JK, Dickens C, Greenwood RM, Mahler RF, Rinsler M. Repeatability, sensitivity and specificity of spot urine albumin/creatinine Repeatability, sensitivity and specificity of spot urine albumin/creatinine
ratios against overnight excretion rates. Diabetic Med 1987;4:385. ratios agains

34 Cruickshank JK, Anderson NMcF. A trial of verapamil compared with metoprolol in black and white hypertensive diabetics. $\mathcal{f}$ Cardiovas Pharmacol 1987;10(suppl 10):85. [Abstract.]

(Accepted 26 fuly 1988 ,
Department of Surgery,

Charing Cross and

Westminster Medical

School, London W6 8RP

Stephen D Blair, FRCS, senior surgical registrar

David D I Wright, FRCS,

lecturer in surgery

Christopher M Backhouse,

FRCS, surgical registrar

Elizabeth Riddle, SRN,

research assistant

Charles N McCollum, FRCs,

reader in surgery

Correspondence to: $\mathrm{Mr}$ McCollum.

\title{
Sustained compression and healing of chronic venous ulcers
}

\author{
Stephen D Blair, David D I Wright, Christopher M Backhouse, Elizabeth Riddle, \\ Charles N McCollum
}

Abstract

Study objective-Comparison of four layer bandage system with traditional adhesive plaster bandaging in terms of $(a)$ compression achieved and (b) healing of venous ulcers.

Design-Part of larger randomised trial of five different dressings.

Setting-Outpatient venous ulcer clinic in university hospital.

Patients - (a) Pressure exerted by both bandage systems was measured in the same 20 patients. (b) Healing with the four layer bandage was assessed in 148 legs in 126 consecutive patients (mean age 71 (SE 2); range 30-96) with chronic venous ulcers that had resisted treatment with traditional bandaging for a mean of $27 \cdot 2$ (SE 8) months.

Interventions - (a) Four layer bandage system or traditional adhesive plaster bandaging for pressure studies; (b) four layer bandaging applied weekly for studies of healing.

End points-(a) Comparison of pressures achieved at the ankle for up to one week; (b) complete healing within 12 weeks.

Measurements and main results-(a) Four layer bandage produced higher initial pressures at the ankle of 42.5 (SE 1) mm Hg compared with 29.8 (1.8) for the adhesive plaster $(p<0.001 ; 95 \%$ confidence interval 18.5 to 6.9). Pressure was maintained for one week with the four layer bandage but fell to 10.4 (3.5) $\mathrm{mm} \mathrm{Hg}$ at 24 hours with adhesive plaster bandaging. (b) After weekly bandaging with the four layer bandage 110 of 48 venous ulcers had healed completely within 12 (mean $6.3(0.4)$ ) weeks.

Conclusion-Sustained compression of over $40 \mathrm{~mm} \mathrm{Hg}$ achieved with a multilayer bandage results in rapid healing of chronic venous ulcers that have failed to heal in many months of compression at lower pressures with more conventional bandages.

\section{Introduction}

Venous or gravitational ulcers result from failure of the calf muscle pump due to venous incompetence, 